\title{
Meta cognitive Strategy Usage and Epistemological Beliefs of Primary School Teacher Trainees: An Explorative Study
}

\author{
Parkash Chandra Jena ${ }^{1, *}$, Latif Ahmad ${ }^{2}$ \\ ${ }^{1}$ Lovely School of Education, Lovely Professional University, Kothi No-522, Urban Estate, Phagwara, \\ Kapurthala, Punjab - 144401, India \\ Mobile \& Landline Number (s): 09876654904 \\ ${ }^{2}$ Research Scholar, School of Education, Lovely Professional University, Punjab, India \\ *E-mail address: drpcjena@gmail.com
}

\begin{abstract}
The main purpose of the study is to identify different levels of metacognition and epistemological beliefs of primary school teacher trainees. The investigator has taken 300 primary school teacher trainees from three districts of Jammu and Kashmir by using simple random sampling technique. For collection of data the investigator has used Metacognitive Inventory (MCI) by Punita Govil and Epistemological Belief Questionnaire (EBQ) constructed and standardized by the investigators. For analyses and interpretation of data the investigator has used percentage and Pearson's Co-efficient of Correlation.
\end{abstract}

Keywords: Metacognitive; Epistemological Belief; Innate Ability Belief; Simple Knowledge Belief; Certain Knowledge Belief

\section{INTRODUCTION}

Globalization and advancements in technology are driving changes in the social, technological, economical, environmental and political landscapes at a rate and magnitude that is too great, and too multiple to ignore. As society changes, the skills that students need to be successful in life also change. Basic literacy skills of reading, writing, and arithmetic are no longer sufficient. Our students need to master those basic skills as well as read critically, write persuasively, think and reason logically, and solve complex problems.

A successful student must be adept at managing information, finding, evaluating and applying new content understanding with great flexibility. They must be equipped with skills and perspectives designed to help them anticipate change. This is possible only by the help of teachers, who possess the potentialities like metacognitive thinking and mature beliefs towards knowledge.

Metacognition is the understanding and awareness of one's own mental or cognitive process. The metacognition is very helpful for distance learners. In distance education, there is no face to face interaction between learner and teacher to understand the content, and clarify 
the difficulties. In this scenario, the learner has to learn the content by himself or herself. There is a dynamic relationship between the leaner, and the learning materials. This dynamic relationship activates through metacognition. Metacognition involves self correction, self assessments, and self reflection. So these elements become essential in distance education environment, where the learner learns the materials by using strategies of self assessments, self reflection, and self evaluation.

Epistemological beliefs are those concerning the nature of knowledge and knowing. These beliefs actually affect interpretation of learning tasks and comprehension. In the field of education, epistemological belief is an important construct, and is frequently used to predict achievement of the students. Epistemological beliefs are considered to be a lens through which individuals interpret information, set standards, and decide on an appropriate course of action. There is an increased need to recognise the students' beliefs about knowledge that influence their behaviour and academic achievements through cognitive, self-regulated learning strategies and decision making skills.

Teachers with developed epistemological beliefs are able to apply their plan for instruction based on students' level of epistemology. These beliefs are likely to influence how students learn, how teachers instruct and subsequently how teachers modify students' epistemological beliefs. A clearer understanding of sophisticated personal epistemology will be useful for adult educational contexts within spiritual communities, where a belief in absolute or certain revealed knowledge is more likely to be a shared intellectual value.

\section{Objectives of the Study}

To explore different levels of metacognition of primary school teacher trainees.

To explore different levels of epistemological beliefs of primary school teacher trainees.

To find out the relationship between metacognition and epistemological beliefs of primary school teacher trainees.

\section{Hypotheses of the Study}

There exists no significant difference in metacognitive strategy usage of primary school teacher trainees so far as the gender is concerned.

There is no significant relationship between metacognition and epistemological beliefs of primary school teacher trainees.

\section{METHOD}

Present study is explorative one and descriptive survey method has been used by investigator. The sampling frame of the study comprises all primary school teacher trainees of three districts of Jammu and Kashmir namely Anantnag, Budgam and Pulwama.

The investigators have selected 300 primary school teacher trainees as sample from six teacher training institutions by using simple random sampling technique with equal proportion of male and female.

\section{1. Tools Used}

Following tools have been used for the data collection.

Metacognitive Inventory (MCI) constructed and standardized by Punita Govil in 2003

Epistemological Belief Questionnaire (EBQ): constructed and standardized by investigators in 2011. 


\section{2. Statistical Techniques Used}

Following statistical techniques have been used for data analyses and for interpretation of results:

Percentage and Pearson's Co-efficient of Correlation.

\section{RESULT PERTAINING TO THE DIFFERENT LEVELS OF METACOGNITION OF PRIMARY SCHOOL TEACHER TRAINEES}

For the classification of different levels of metacognition of 300 primary school teacher trainees, the investigators have used Metacognitive Inventory constructed and standardized by Punita Govil and result is presented in Table 1.

Table 1. Frequency and Percentage of Primary School Teacher Trainees in the Different Levels of Metacognition.

\begin{tabular}{|c|c|c|c|}
\hline S. No. & Levels of Metacognition & Frequency & Percentage \\
\hline 1. & Very High & 6 & $2 \%$ \\
\hline 2. & High & 88 & $29 \%$ \\
\hline 3. & Average & 145 & $49 \%$ \\
\hline 4. & Low & 57 & $19 \%$ \\
\hline 5. & Very Low & 4 & $1 \%$ \\
\hline & Total & 300 & $100 \%$ \\
\hline
\end{tabular}

The table no. 1 shows the distribution of three hundred primary school teacher in the different levels of metacognition. The percentage of primary school teachers in different levels of metacognition are very high (2\%), high (29\%), average (49\%), low (19\%) and very low (1 $\%)$. The same has been shown in Figure 1 and 2. 


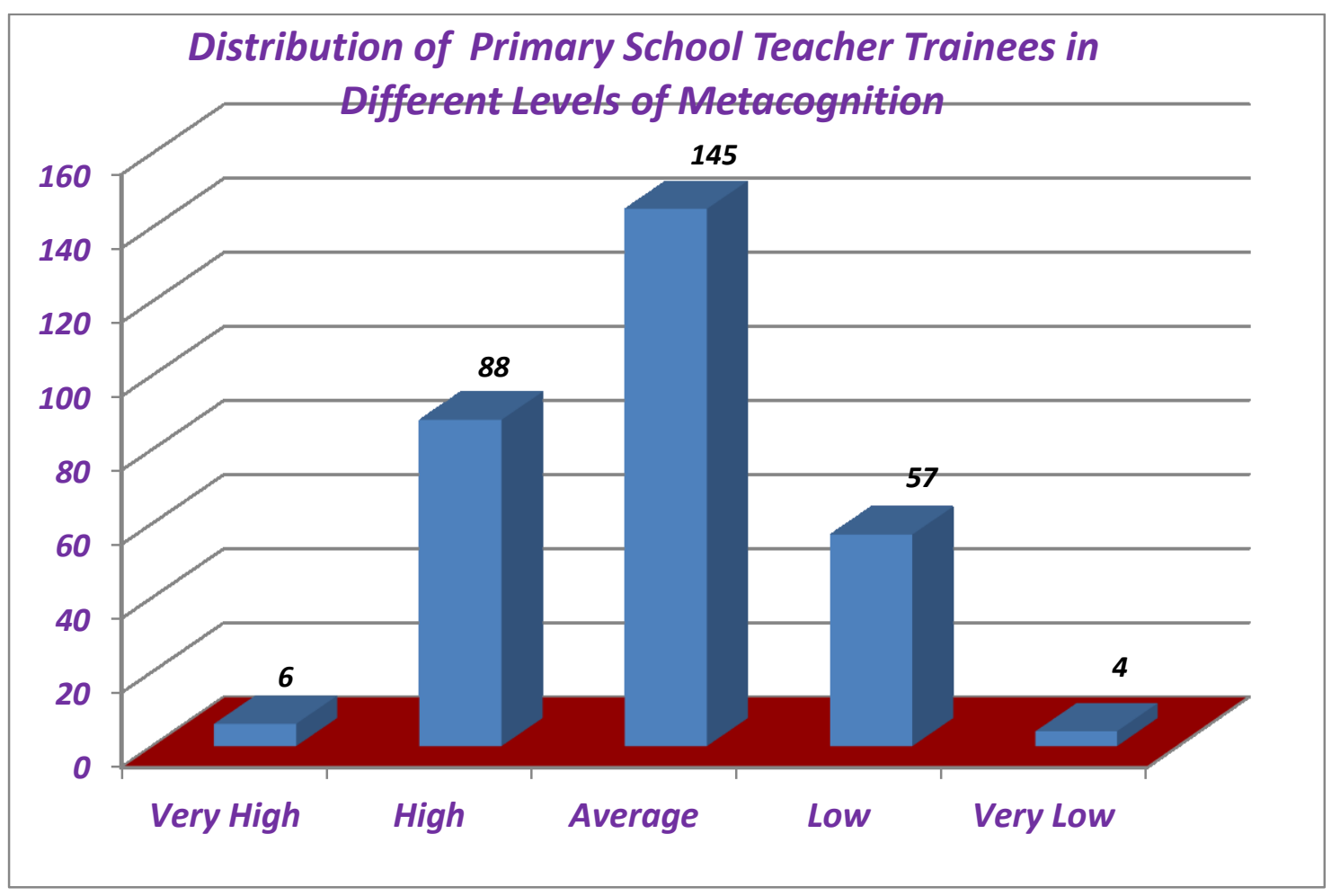

Figure 1

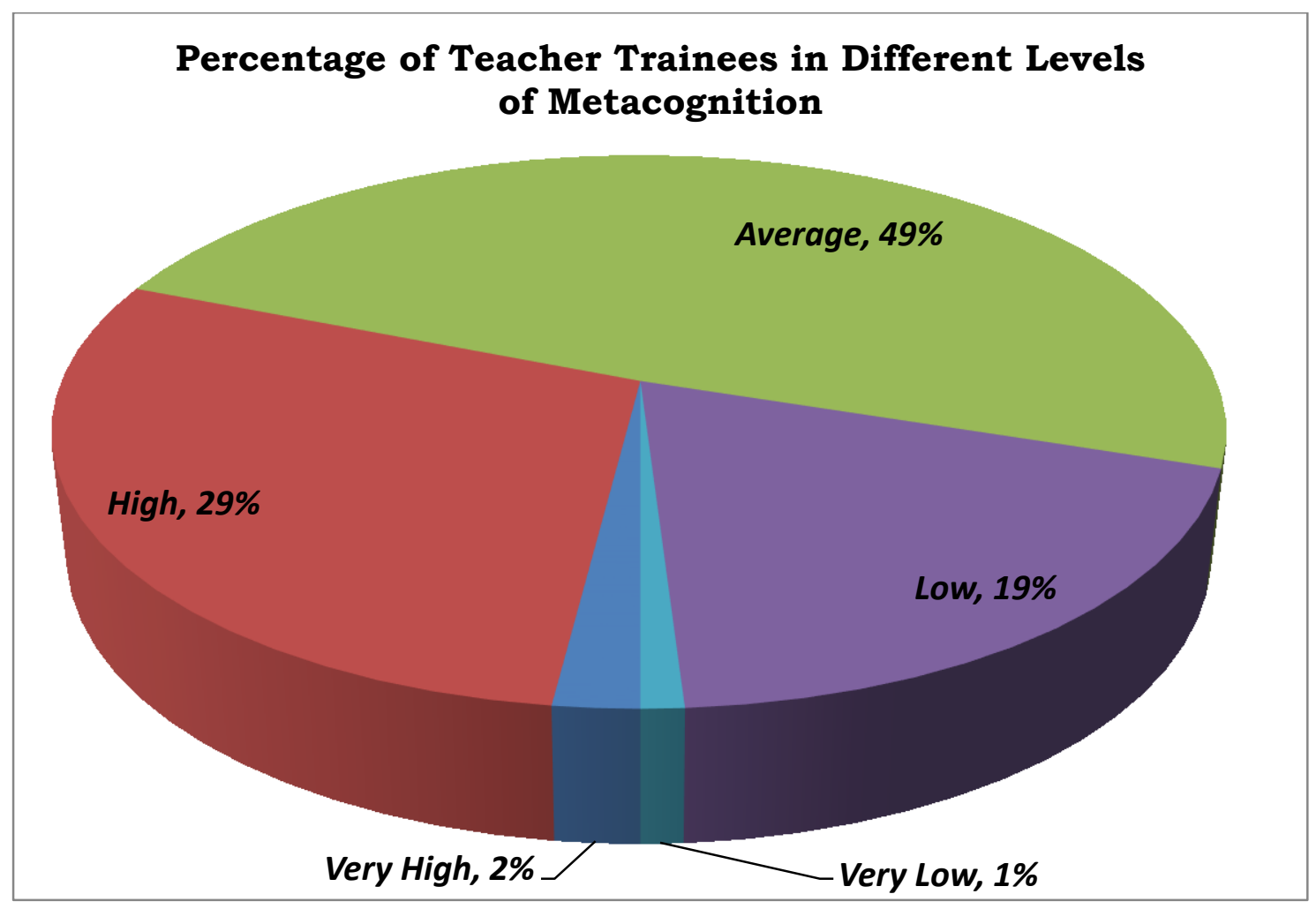

Figure 2 


\section{RESULT PERTAINING TO THE DIFFERENT LEVELS OF EPISTEMOLOGICAL BELIEF OF PRIMARY SCHOOL TEACHER TRAINEES}

For the classification of different levels of epistemological belief of 300 primary school teacher trainees, the investigators have used Epistemological Belief Questionnaire (EBQ) constructed and standardized by investigators and the result is presented in Table 2.

Table 2. Frequency and Percentage of Primary School Teacher Trainees in Different Levels of Epistemological Belief.

\begin{tabular}{|c||c|c|c|}
\hline S. No. & Levels of Epistemological Belief & Frequency & Percentage \\
\hline 1. & Mature & 71 & $24 \%$ \\
\hline 2. & Moderate & 191 & $64 \%$ \\
\hline \hline 3. & Naive & 38 & $12 \%$ \\
\hline \hline \multicolumn{2}{|c|}{ Total } & 300 & $100 \%$ \\
\hline
\end{tabular}

Table 2 reveals that majority (64\%) teacher trainees were identified as having moderate epistemological belief, $24 \%$ teacher trainees were identified as possessing mature epistemological beliefs and $12 \%$ possess naive epistemological belief. The same has been shown in Figure 3 and 4 below.

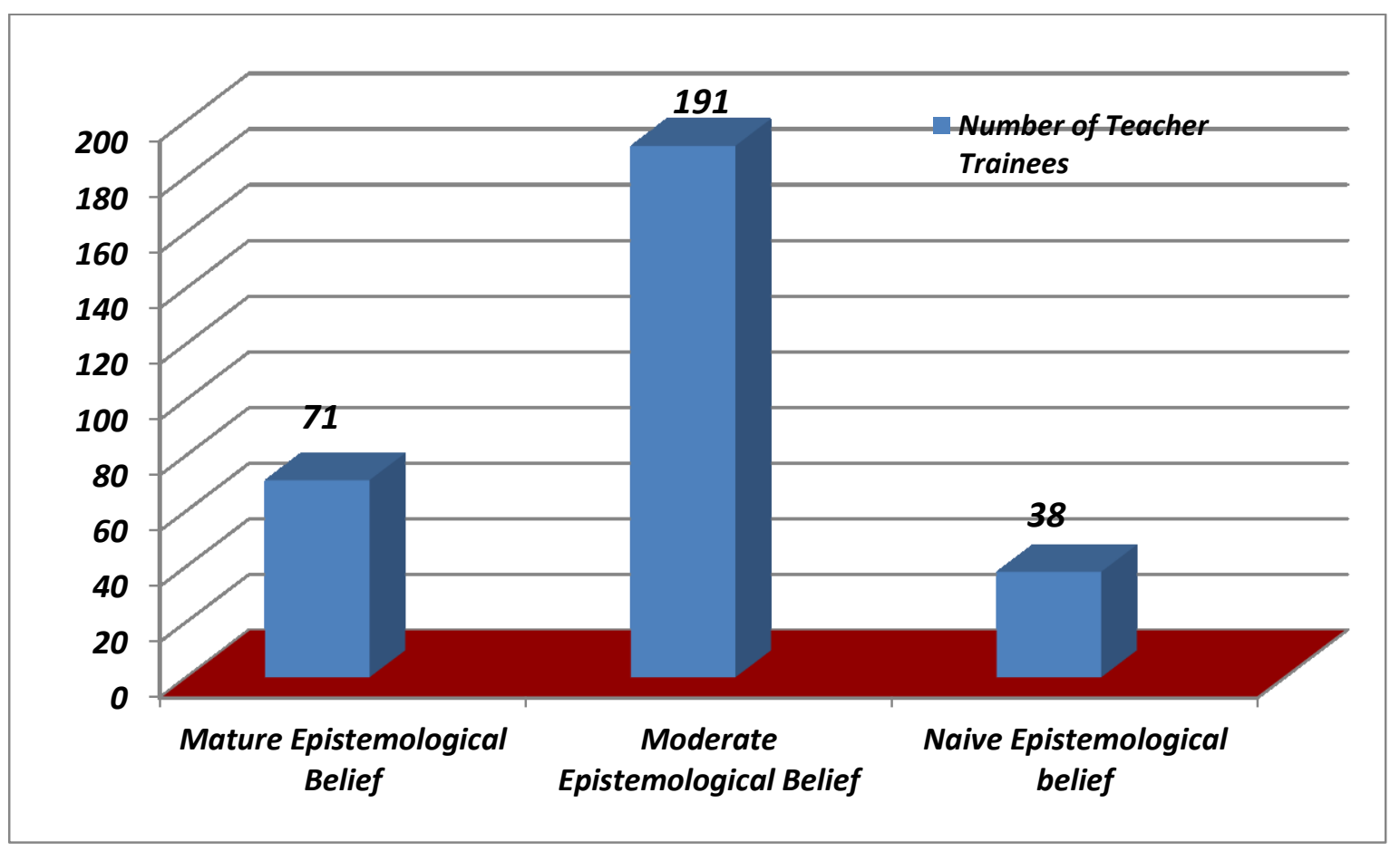

Figure 3. Bar Graph showing the Frequency of Primary Teacher Trainees in Different Levels of Epistemological Belief. 


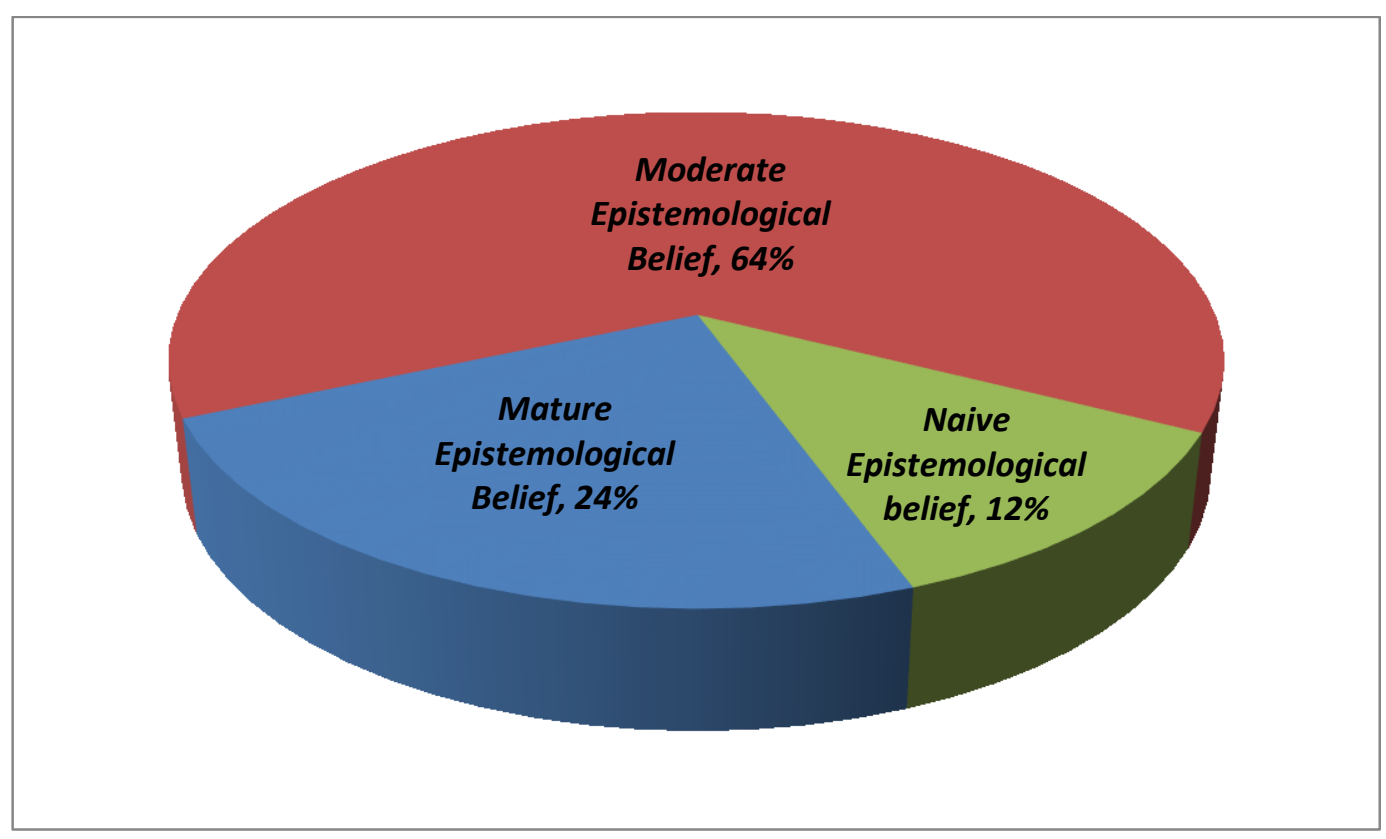

Figure 4. Pie Chart showing the Percentage of Primary School Teacher Trainees in the Different Levels of Epistemological Belief.

\section{RESULTS PERTAINING TO THE RELATIONSHIP BETWEEN METACOGNITION AND EPISTEMOLOGICAL BELIEF OF PRIMARY SCHOOL TEACHER TRAINEES}

To find out the relationship between metacognition and epistemological belief of primary school teacher trainees, Pearson's correlation co-efficient was applied and the result was presented in Table 3.

Table 3. Results of Co-efficient of correlation between Metacognition and Epistemological Belief of Primary School Teacher Trainees.

\begin{tabular}{|c||c|c||c|c|}
\hline Variables & N & df & r & Significance \\
\hline Metacognition & \multirow{2}{*}{300} & 298 & 0.464 & $\mathrm{P}<0.01$ \\
\hline Epistemological Belief & & & & \\
\hline
\end{tabular}

(Value of "r" at 0.05 and 0.01 Levels of Significance are 0.11 and 0.148 )

The Table 3 depicts that the co-efficient of correlation between metacognition and epistemological beliefs among primary school teacher trainees is greater than the table at both the levels. It is concluded that there exists a significant relationship between metacognition and epistemological beliefs of primary school teacher trainees. Therefore the hypothesis no. 5 which reads as "there is no significant relationship between metacognition and epistemological beliefs 
of primary school teacher trainees" was rejected. Positive relationship between metacognition and epistemological belief reveals that the teacher trainees who were more aware about their metacognitive strategies possess sophisticated epistemological beliefs.

The results were in correlation with the findings of Kuhn (2001), who stated "To fully understand processes of knowing and knowledge acquisition, it is necessary to examine people's understanding of their own knowledge".

\section{RESULT ANALYSIS AND MAIN FINDINGS}

\section{1. Levels of meta cognition of primary school teacher trainees}

So for as the levels of metacognition of three hundred teacher trainees is concerned, it has been found that $2 \%$ teacher trainees have very high level of metacognition, $29 \%$ have high level, $49 \%$ have average level, $19 \%$ have low level and $1 \%$ have very low level of metacognition.

\section{2. Levels of epistemological beliefs of primary school teacher trainees}

Regarding the levels of epistemological belief of three hundred teacher trainees, majority of teacher trainees $(64 \%)$ were identified as having moderate epistemological belief, $24 \%$ teacher trainees were identified as possessing mature epistemological beliefs and $12 \%$ possessing naive epistemological belief.

\section{3. Relationship between metacognition and epistemological belief of primary school teacher trainee}

There exists a positive significant relationship between metacognition and epistemological beliefs of primary school teacher trainees. Significant positive relationship was also found between metacognition and epistemological belief of male primary school teacher trainees.

\section{SUGGESTIONS FOR FURTHER RESEARCH}

The following suggestions for future research that could be conducted by prospective researchers are:

The present study was conducted on pre-service primary school teacher trainees, a similar study can be conducted on in-service and B. Ed. Teacher trainees.

In this study metacognition and epistemological beliefs of respondents were studied with respect to gender and academic achievement. The further study can be conducted with respect to socio-economic status of family, location, grade level of respondents and level of education of parents.

Teachers' role in developing young children metacognition and epistemological belief is important. Thus further research can be conducted to investigate the affects of teachers' behavior and teaching styles on development of children's metacognition and epistemological beliefs.

In this study, data were collected by using questionnaires only. In further study, qualitative data can be gathered by interviewing the respondents. 
The data was collected from three districts of Jammu and Kashmir namely district Anantnag, Budgam, and Pulwama. A similar study can be conducted in other districts of Jammu and Kashmir and other parts of India.

\section{RECOMMENDATIONS - CONCLUSIONS}

$>$ The teachers and teacher educators should be informed about the importance of metacognition and epistemological beliefs and should be explained how they can develop students' metacognition and mature epistemological beliefs throughout their formal education.

$>$ The teachers should improve their students' metacognitive awareness in order to improve their learning abilities. The more students know about effective learning strategies, the higher their classroom achievement is likely to be. Creating a metacognitive learning environment in a classroom is the responsibility of teacher. He should allow the students to seek understanding by exploring and investigating on their own with teacher as facilitator. He can also use strategies for encouraging meta cognition in classroom.

$>$ Teachers should take special care to encourage the students to evaluate new information critically to avoid biased assimilation.

$>$ Teacher educators should instruct prospective teachers about the effective study skills, metacognitive skills and use of metacognitive skills during study.

$>$ Curriculum framers should include activities based on metacognitive skills, especially effective study skills in a more comprehensible way.

$>$ Both central as well as state governments should introduce computers in educational institutions because these have a lot of potential as metacognitive tools. Computers through their ability to interact with users, they can become powerful reflection tools. This will help the student to become aware of his/her processes and help him/her to improve performance on the task in question through reflection on the how's and why's of the chosen problem solving paths.

$>$ Epistemology exists in the form of beliefs, and learning is influenced by the epistemological beliefs that individuals hold. Therefore educators and teachers should develop mature beliefs in students. They should inform students that knowledge is integrated and that many times there is more than one right answer.

$>$ The results revealed that teacher trainees with high academic achievement have more mature beliefs and metacognitively more aware than with low academic achievement. Therefore the students with low academic achievement need to be considered by teachers in order to increase their achievement in different subjects. They should arrange instructional methods, classroom activities, and constructivist learning environment.

$>$ Teacher educators should appraise the pupil teachers about different epistemological beliefs so that they could understanding the epistemological underpinnings of their students' approaches to learning and academic subjects and help them to consolidate their current constructions of learning and move them forward to more sophisticated constructions. 


\section{References}

[1] Brownlee, J. (2001). Changes in Primary School Teachers' Beliefs about Knowing: A Longitudinal Study. Asia-Pacific Journal of Teacher Education, 31(1), 87.

[2] Ching, S. C., Feng, D., Benjamin, W. Yangyi, Q. (2010). South China Education Majors' Epistemological Beliefs and their Conceptions of Nature of Science. Asia Pacific Education Research, 19(1), 111-125.

[3] Dominik, G., Brian, W. (2007). Metacognition of Problem Solving Strategies in Brazil, India, and the United States. Journal of Cognition and Culture, 7(3), 1-25.

[4] Fracisco, C. (2005). Epistemological Beliefs and Approaches to Learning: Their Change Through Secondary School and their Influence on Academic Performance. British Journal of Educational Psychology, 75(12), 203-221.

[5] Gulsum, A., Semra, S., Ceren, T. (2010). The Contribution of Cognitive and Metacognitive Strategies Use to Students' Science Achievement. Educational Research and Evaluation, 16(1), 1-21.

[6] Harun, Y. and Sami, S. (2011). Pre-service Teachers' Epistemological Beliefs and Conceptions of Teaching. Australian Journal of Teacher Education, 36(1), 73-88.

[7] Helen, N. (2009). Metacognitive Strategies on Classroom Participation and Student Achievement in Senior Secondary School Science Classroom. Science Education International, 20 (7), 79-93

[8] Hwang, Y. S., Vrongistinos, K. (2002). Elementary In-service Teachers' Self-regulated Learning Strategies Related to their Academic Achievements. Journal of Instructional Psychology, 29(3), 147-155.

[9] Ken, R. L. (2007). Relation among Epistemological Beliefs, Academic Achievement and Task Performance in Secondary School Students. Educational Psychology, 27 (3), 307-327.

[10] Schoenfeld, A. H. (1983). Beyond the Purely Cognitive: Belief systems, Social Cognitions, and Metacognitions as Driving Forces in Intellectual Performance. Cognitive Science, 7(6), 329-363.

[11] Schommer, M. (1990). The Effects of Beliefs About the Nature of Knowledge on Comprehension. Journal of Educational Psychology, 82(3), 498-504.

[12] Schommer, M. (1993). Epistemological Development and Academic Performance among Secondary Students. Journal of Educational Psychology, 85, 406-411. 
[13] Schommer, M. (2002). An Evolving Theoretical Framework for an Epistemological Belief System. In B.K. Hofer and Pintrich (Ed). Personal Epistemology: the Psychology of beliefs about knowledge and knowing (pp 103-118). Mahwah, NJ: Lawrence Erlbaun Associates, Inc.

[14] Schommer, M. (2004). Explaining the Epistemological Belief System: Introducing the Embedded Systematic Model and Coordinated Research Approach. Educational Psychology, 39(5), 19-29.

[15] Schommer, M., Hutter, R. (2002). Epistemological Beliefs and Thinking about Everyday Controversial Issues. The Journal of Psychology, 136(1), 5-20. 